\begin{tabular}{ll}
\hline $\begin{array}{l}\text { Social Work/Maatskaplike Werk Vol } 57 \text { No 1; Issue } 5 \\
\text { http://socialwork.journals.ac.za/pub }\end{array}$ & doi:http://dx.doi.org/10.15270/52-2-907 \\
\hline
\end{tabular}

KEY INFORMANTS' PERSPECTIVES ON FOOD SECURITY AMONG FEMALE-HEADED HOUSEHOLDS IN KENYA

Beatrice Kabui Icheria, Charlene Laurence Carbonatto, Nontembeko Joyce Bila

Social connectedness plays an important role in protecting food security, which requires multidisciplinary input from fields such as nutrition, agriculture, public health, social work and community development. This qualitative study explored food security among female-headed households (FHHs) in Kenya, as part of a larger mixed methods doctoral study. Fifteen key informants monitoring food security were interviewed in the qualitative phase and the thematic analysis generated nine themes, of which two are discussed. Results reveal that dietary diversity in FHHs is poor: they often experience severe food insecurity. Recommendations for practice, policy, and future research are provided.

Keywords: dietary diversity, female-headed households, food security, nutrition, poverty, social work 


\title{
KEY INFORMANTS' PERSPECTIVES ON FOOD SECURITY AMONG FEMALE-HEADED HOUSEHOLDS IN KENYA
}

\author{
Beatrice Kabui Icheria, Charlene Laurence Carbonatto, Nontembeko Joyce Bila
}

Dr Beatrice Kabui Icheria, Doctoral candidate, Department Social Work and Criminology, University of Pretoria, Pretoria, South Africa.

Dr Charlene Laurence Carbonatto, Department Social Work and Criminology, University of Pretoria, Pretoria, South Africa.

Dr Nontembeko Joyce Bila, Department Social Work and Criminology, University of Pretoria, Pretoria, South Africa.

Keywords: dietary diversity, female-headed households, food security, nutrition, poverty, social work

\section{INTRODUCTION}

This study was conducted against the backdrop of two of the United Nations' (UN's) global Sustainable Development Goals (SDGs), namely SDG1: End poverty in all its forms everywhere, and SDG2: End hunger, achieve food security and improved nutrition and promote sustainable agriculture (UN, 2015:3). According to a joint publication by the Food \& Agriculture Organisation of the United Nations (FAO), the International Fund for Agricultural Development (IFAD), the United Nations International Children's Fund (UNICEF), the World Food Programme, (WFP) and the World Health Organization (WHO), globally in 2017 an estimated 821 million people, in other words, approximately one out of every nine people or $10.9 \%$ of the world's population, suffered from undernourishment (FAO, IFAD, UNICEF, WFP \& WHO, 2018:2). Undernourishment and severe food insecurity appear to be increasing in almost all regions of Africa and South America (FAO et al., 2018:2).

In sub-Saharan Africa (including Kenya), the poorest region in the world (Chauvin, Mulangu \& Porto, 2012:1), the number of undernourished people rose from 181 million in 2010 to 236 million in 2017; this means that one in four people (23.2\%) in the region were suffering from food deprivation. In East Africa, where Kenya is situated geographically, the level is even higher, at 31.4\% (FAO et al., 2018:4). Poverty is the main cause of food insecurity globally (World Bank, 2016), causing and exacerbating food insecurity, especially in Africa and other developing countries, where war/civil strife and gender inequality contribute to the problem (Mwaniki, 2015:1). In Africa, the prevalence of food insecurity in 2017 among women was marginally higher (24.3\%) than among men (23.9\%) (FAO et al., 2018:10).

Food insecurity is thus a social and economic problem that affects the physical and mental health of millions of people (Paul, 2011). Hence, the authors of this article regard food security as an important field for the social work profession, because social work, with its broad-based scope and focus on helping, is ideally suited to help promote food security (Ragan \& Dimitropoulus, 2017). The article argues that the ecological systems perspective may be helpful in understanding how social work can play a role on all levels in this regard. However, a review of social work literature suggests that food security is not as high on the list of social work priorities as social problems such as housing, gender-based violence and mental health. This gap in the literature therefore motivated this study amongst female-headed households (FHHs) in Kenya - where the first author, a Kenyan, resides.

This article offers a brief overview of the literature, followed by an account of the theoretical framework underpinning the study. Then an outline of the problem statement, research question, research methodology and methods of the study is provided, and the findings, discussion, conclusions and recommendations are presented. 


\section{LITERATURE OVERVIEW}

The World Food Summit in 1996 explained that food security "exists when all people, at all times, have physical and economic access to sufficient, safe and nutritious food that meets their dietary needs and food preferences for an active and healthy life" (FAO, 2008:1). The four dimensions of food security are food availability, food access, food utilisation and food stability. According to the FAO (2008:1), food availability addresses the "supply side" of food security; food access is determined by income, expenditure, markets and prices; food utilisation is commonly understood as the way the body makes the most of various nutrients in the food; and food stability is achieved through the stability of the other three dimensions over time. These dimensions must all be addressed simultaneously to achieve food security (FAO, 2008:1).

The combination of moderate and severe levels of food insecurity brings the estimate to 26.4 percent of the world population, amounting to a total of about 2 billion people who are food insecure (FAO, IFAD, UNICEF, WFP \& WHO, 2019:xvii). Food security is thus a key issue from a global political economy perspective, because, as policy-makers in international institutions such as the World Trade Organization and the UN argue, it is directly related to the way in which developing countries can benefit from constant changes in global agricultural trade (Phillips, 2009). Nutrition is central to the UN's (2015) 2030 Agenda for Sustainable Development, as good nutrition lays the foundation for achieving many of the SDGs (FAO et al., 2018:13). This means that good nutrition is the lifeblood of sustainable development and drives the changes needed for a more sustainable and prosperous future.

Addressing food insecurity is challenging because so many different groups are involved, and the interests of those groups often compete. It is also difficult to ensure the feasibility of creating changes within complex global food systems. The concept of community food security implies equitable access to healthy foods grown in a sustainable, environmentally friendly way. This approach offers both a framework and an intervention strategy to address interrelated social, economic and environmental issues. As a social development intervention, it can be a solution to economic development and equitable resource distribution (Kaiser, 2011).

Hunger, poverty and malnutrition are all related to food insecurity (FAO, 2008:3), but the terms are not synonymous. Hunger refers to food deprivation or an uncomfortable or painful sensation caused by insufficient food energy consumption. Poverty is a broad term that encompasses different dimensions of deprivation that relate to human capabilities, including consumption and food security, health, education, rights, voice, security, dignity and decent work (OECD in FAO, 2008:3). Malnutrition results from deficiencies, excesses or imbalances in the consumption of macro- and/or micronutrients; it may be the outcome of food insecurity, or it may relate to non-food factors such as inadequate care practices for children, insufficient health services and an unhealthy environment (FAO, 2008:3). Social workers can play an active role in dealing with poverty and hunger. Health social workers in particular play a role predominantly with regard to cases of malnutrition amongst children - some prior studies have provided a number of practice recommendations (Booi, 2001; Ditebo, 2010). Thus social workers are often already indirectly involved in the mitigation of food insecurity, and are therefore well positioned to implement interventions, but a literature search suggests that no explicit guidelines have been published on the role that social workers can or should play in helping to ensure food security.

Food consumption, food security, health and rights are all encompassed by the broader dimensions of deprivation and poverty. Thus food security and poverty go hand in hand -according to the World Bank (2016), poverty is the main cause of food insecurity globally. Food insecurity is a problem of inequality that disproportionately affects minorities and vulnerable populations. Food insecurity is a matter of social justice, which implies that social workers have an ethical responsibility to address it, as is confirmed by the Code of Ethics of the National Association of Social Work (NASW, 2017). Social workers can mitigate issues of poverty by connecting clients to services and entitlements, but the literature indicates that food insecurity is not commonly addressed in practice. Further studies of the experience and 
understanding of social workers in the area of food insecurity are needed to advance work in this critical area (Paul, 2011).

Food security is necessary for healthy physical, mental and emotional development (Mikkonen, \& Raphael, 2010). Those affected by food insecurity tend to require more medical intervention, resulting in increased health costs (Ragan \& Dimitropoulos, 2017). Moreover, Qureshi, Dixon and Wood (2015:395) point out the role played by health deprivation and undernutrition in creating and maintaining poverty traps, identifying maternal and child undernutrition as the primary pathway by which poverty is transmitted from one generation to the next. Therefore, in order to ensure food security as a human right, the implementation of gender-based food policies and plans is urgently required. Social workers need to understand how poverty relates to food insecurity and the importance of this in the human developmental trajectory, especially that of children. The potential benefits of comprehending and managing these relations to both the social work profession and society are immeasurable (Ragan \& Dimitropoulus, 2017).

FAO et al. (2019:xvi) emphasise that hunger is on the rise in almost all sub-regions of Africa, where the prevalence of undernourishment has reached levels of 22.8 percent in sub-Saharan Africa. Undernourishment refers to the proportion of the population whose dietary energy consumption is less than a pre-determined threshold (which is country-specific), measured in terms of the number of kilocalories required to conduct sedentary or light activities. The undernourished are also referred to as those who suffer from food deprivation (FAO, 2008:2). The prevalence of undernutrition is the traditional indicator used to monitor hunger at the global and regional level (FAO et al., 2018:7). Hence, the fact that undernutrition is increasing in Africa is a sign of increasing hunger and food insecurity, warning all policy-makers that much more needs to be done to achieve SDG2 (FAO et al., et at., 2018:2). Paradoxically, food insecurity contributes to people's becoming overweight or obese, as well as to undernutrition. The higher cost of nutritious foods, the stress of living with food insecurity and physiological adaptations to food restrictions help to explain why food-insecure families may have a higher risk of obesity (FAO et al.,et al., 2018:xiv). Mikkonen and Raphael (2010) mention in this regard that as stress in the home increases, so might the use of alcohol, cigarettes and consumption of carbohydrates. Factors that help to explain the link between food insecurity and overweight and obesity include the higher cost of nutritious foods (and their substitution with cheaper foods that are high in fats and sugar), the stress of living with uncertain access to food, and physiological adaptations to food restrictions (FAO et al., 2019:xviii). Multifaceted, multisectoral approaches are thus needed to halt and reverse the obesity epidemic (FAO et al., 2019:xvii).

Food and nutrition security and gender equality are also closely linked and mutually constitutive (Brody, Hossain, Oswald \& Smith, 2015:2). If women are to lead poverty recovery at the grassroots level, their health has to be a primary consideration (Phillips, 2009). Women play a central role in food security and therefore experience double jeopardy when the food supply diminishes, or food becomes inaccessible because of price increases. The connection between women and food security is not an issue confined to the developing world, but arises globally where there is poverty, including some wealthy countries (Rideout, Riches, Ostry, Buckingham, \& MacRae, 2007). The fact that women and girls are among the most undernourished globally and are often hardest hit by food insecurity underlines this (Brody et al., 2015:2). Besides facing challenges of feeding themselves, women also bear the burden of nurturing children, who require proper feeding for physiological growth and development.

Food meets a primary need and can provide pleasure - it constitutes an "immediate reality", in which various food substances, preparation techniques and customs all contribute to systems which may differ significantly in various regions (Barthes, n.d. in Counihan \& Van Esterik 2008:76). Like food, the practice of social work is entwined - often in the most intimate way - with the most integral events in people's lives: birth, death, the formation and dissolution of relationships. Social workers are frequently directly involved in the provision of food, or education about food (Apaitia-Vague, 2011). Thus, social 
work's core value of social justice responds directly to communities' need to access and consume food, especially nutritious and culturally appropriate and fulfilling food.

Social workers must play a role in working with clients who explicitly present with eating disorders, and in assessing the food security status of families. When social workers explore the nutrition status of families, they should ensure that the questions they ask about which foods are consumed are not directed only at the mother in the family (Apaitia-Vague, 2011). Social workers should also ask about family meals and consider using assessment tools as part of the overall treatment plan. For example, the SocioEconomic Empowerment Assessment (SEEA), which is based on an ecological multi-systems perspective, can situate the family's financial situation within their psychological, cultural and lifeexperience contexts (Chilton, Knowles \& Rabinowich, 2015), and it is in line with the ecological systems perspective underpinning this study (discussed under the theoretical framework presented in the next section). Another helpful tool is the Household Food Security Survey Model (HFSSM), which can be used with adults; there is a shorter version for children to determine the level of household food insecurity (HFI) (Hawkins \& Kim, 2012).

Food sharing is a deeply ingrained social activity, so food-sharing networks have been studied for their role in building and maintaining cultural identity and social bonds (Koster \& Leckie, 2014; Nolin, 2010; Trostle, Hubbard, Scott, Cevallos, Bates \& Eisenberg, 2007). These reciprocal relations and interactions may also increase household and community-level resilience by helping to maintain food security during periods of seasonal scarcity, or following climatic or economic shocks (Adger, 2003; Hadley, Mulder \& Fitzherbert, 2007; Sherman, Ford, Llanos-Cuentas \& Valdivia, 2016). Conversely, chronic pressure on food resources that reduces food sharing may erode social capital (Hadley, Stevenson, Tadesse \& Belachew, 2012; Sherman et al., 2016).

From an ecological systems perspective, resources and linkages from a wide range of disciplines are embedded in each system level in society. Social developers evaluate processes in terms of systems that promote sustainable economic, environmental and social justice interactions between the various social and ecological environments (Kaiser, 2011). For example, social workers can work with farmers to determine how to increase access to nutritional foods for low-income families, by identifying accessible locations where food can be picked up, encouraging the planting of culturally specific foods, or facilitating donations of extra produce to food pantries or soup kitchens (Kaiser, 2011). Social workers have a unique set of community practice knowledge and skills that can help communities achieve greater access to affordable, healthy food. They can therefore help build interdisciplinary networks to change food policies and develop sustainable and equitable food systems to address food insecurity (Kaiser, 2011).

Social workers can offer their programme development and evaluation skills to improve the quality and availability of healthy food. Interpersonal, brokering and coalition-building skills can be used to initiate or facilitate communitywide discussions, build trustworthy relationships among people with diverse perspectives, and mobilise community members (Kaiser, 2011). This kind of skills deployment is vital in the context of social development, which Midgley (1995) describes as a process of planned social change designed to promote the wellbeing of the population in conjunction with a dynamic process of economic development. The distributive dimensions of social development theory which are of special concern to social workers focus on social equity between groups. Community participation from a diverse group of stakeholders aims at making structural changes to counter underlying economic and institutional problems in order to achieve social equity, and this is where social workers can contribute, especially if social development interventions use the ecological systems perspective and rely on the use of social capital. At the individual level, people can focus on their contributing behaviours to social problems, while collectivist ideologies emphasise coalition-building and social cohesion at the organisational and group level, and populist ideologies extend activities to small communities (Kaiser, 2011), and social workers can engage fruitfully at all these levels. 
Social workers can also help build community food services using their skills of advocacy and collaboration to promote the availability and affordability of healthy food options, because a lack of access to nutritious food has been found to increase the consumption of fast foods (Besthorn, 2013; Lessa $\&$ Rocha, 2012). Community food services are used to define food-related issues, plan strategies for change, and gather support from a wide variety of community members (Jacobson, 2007).

Self-reliance is considered a more ethical and sustainable solution than the provision of emergency food, and social workers can help guide their clients in practical ways towards attaining this goal (Himmelheber, 2014). However, social workers need to be mindful of the structural barriers that continually challenge self-reliance, and need to ascertain whether they can help by strengthening communities and advocating for government resources to enhance micro and meso level intervention (Ragan \& Dimitropoulus, 2017).

International social work is engaged in many facets of food and nutrition security - as Riches (2001:1) argues, this field of engagement should be seen by the social work profession as "a pivotal ecological, economic and social justice issue for the 21 st century". However, there are growing imperatives to widen international social work engagement, for example, in vital issues including global warming, as evidence mounts that the world will face extensive, worldwide food security issues in future, as global temperatures rise (Australia Broadcast Corporation, 2005; Rosegrant \& Cline, 2003).

\section{THEORETICAL FRAMEWORK}

This study is underpinned by the ecological systems perspective developed by Bronfenbrenner (1989), in which different levels of ecological systems are viewed as interlinked (Neal \& Neal, 2013:723). The systems should be regarded as networked (Neal \& Neal, 2013:723); each system is defined in terms of the social relationships surrounding an individual, and systems at different levels relate to one another in an overlapping and interlinked way. Networks, particularly collaborations, especially among FHHs and external environments, are essential in the realisation of sustainable food security for everyone. Elliott and Davis (2018:10) observe that children (growing individuals), including those in FHHs are both influenced and influential within these interlinked social systems. Concentric interlinked circles comprise the micro, meso, exo and macro system (Elliott \& Davis, 2018:10), and the chrono system, which includes the aspect of networking through interrelations between multiple environments. Ettekal and Mahoney (2017:3) highlight the meso system as involving processes that occur between the multiple micro systems in which individuals are embedded.

\section{PROBLEM STATEMENT AND RESEARCH QUESTION}

As already indicated above, sub-Saharan Africa is the poorest region in the world (Chauvin et al., 2012:1). In this region, a lack of adequate or proper nutrition is an underlying cause of poverty, and poverty is in turn a cause of hunger (FAO, 2008:3). The global emphasis on poverty and food security is evident in SDG1: End poverty in all its forms everywhere, and SDG2: End hunger, achieve food security, improved nutrition and promote sustainable agriculture (UN, 2015), to help eradicate these problems in a sustainable way.

Undernourishment and severe food insecurity are increasing in Africa and specifically in sub-Saharan Africa (FAO et al., 2018:2). Throughout the continent, women are overburdened with poverty, the main factor underlying food insecurity in Africa and thus suffer a higher prevalence of food insecurity than men (FAO et al., 2018:10). In the case of Kenya, $80 \%$ of poverty-stricken people live in the rural areas and the main contributing factors to poverty amongst women, are low literacy levels and the death of the bread-winner (Mutavi, Kokonya, Obondo, Wariua \& Ocharo, 2013:209).

Climate variability and extremes are among the key drivers behind the recent increase in African and indeed global hunger and food crises (FAO et al., 2018: xvi). Food insecurity in Kenya is caused by climate changes such as recurrent droughts, high fuel prices and globalisation (Republic of Kenya, 2011:5), which is rapidly redefining food affordability and limiting poor people's food consumption, as 
their diets become less balanced and they get fewer frequent meals. Climate changes undermine all dimensions of food security, and reinforce other underlying causes of malnutrition related to child care and feeding, health services and environmental health (FAO et al., 2018:xiv,xvi). This study was thus motivated by the fact that Kenya (among other countries in sub-Saharan Africa) is experiencing increased poverty and consequent food insecurity (FAO et al., 2018:4).

A research gap was identified regarding research on food security among women, and specifically FHHs in Kenya, specifically in Voi Division, Taita-Taveta County. This study thus aimed to investigate and describe food security from an ecological systems perspective among FHHs in Voi Division, TaitaTaveta County, Kenya. Furthermore, practice and policy guidelines are proposed, as well as recommendations for future research for practitioners from various fields, including social work, to understand and adapt their services to contribute towards food security among FHHs as a vulnerable group. The research question was the following: What is the status of food security among femaleheaded households in Voi Division in Taita-Taveta County, Kenya?

\section{RESEARCH METHODOLOGY AND METHODS Research approach and design}

The qualitative phase of the study used a collective case study design to gather key informants' perspectives on food security among FHHs in Voi Division, Taita-Taveta County, Kenya. The study was implemented within an interpretivist research paradigm, as described by Nieuwenhuis (2020), because the authors were interested in the perspectives of the key informants (participants), as expressed in their own words.

\section{Research site}

The study was conducted in sub-Saharan Africa, Southern Kenya, in Taita-Taveta County, specifically Voi Division. The Taita-Taveta County is $380 \mathrm{~km}$ southeast of Nairobi, which is a semi-arid land area, a region where frequent droughts jeopardise crop yields and livestock productivity, leading to household food insecurity. Voi Division lies to the west of the world-famous Tsavo East National Park and is a tourist hub. According to the Kenya National Bureau of Statistics (KNBS), the population of the county was 340,671 in 2018 (KNBS, 2019). The study area was demarcated as Voi Division, with two sublocations, namely Kaloleni and Mwangea.

\section{Study population and sample}

Key informants were chosen as the participants for the study because of their knowledge and expertise regarding food security in the study area. This choice was made in the light of De Clerck, Willems, Timmerman and Carling's (2011:6) recommendation to use key informants who have a broad knowledge of specific research settings or deep knowledge and skills related to important aspects of the research topic. Firstly, organisations where the potential key informants worked were purposively sampled, as suggested by Strydom and Delport (2011), including World Vision and Reach Out Centre Trust (two non-governmental organisations), the Mwatate District Stakeholders' Forum (a community-based organisation), the National Drought Management Authority, the Kenya Red Cross, the Ministry of Agriculture in Voi, and the Ministry of Water and Irrigation in Voi. Next, 15 key informants were identified among the staff of these organisations. The selection criteria were gender representation, being 18 years or older, having a permanent or contractual career with the organisation(s), and having at least one year of work experience in the field of food security and monitoring in the area. The data from one respondent were discarded because the participant admitted at the end of the interview that the person had looked at the interview schedule prior to the interview. Hence, the data of only 14 participants were included.

\section{Data collection and analysis}

Data were collected through one-to-one interviews using a semi-structured interview schedule, as recommended by Nieuwenhuis (2020). Interviews were voice recorded with prior participant permission. The informants signed forms indicating voluntary participation and informed consent. Thematic analysis 
of the transcriptions of the interview recordings followed (Braun \& Clarke, 2013), with rich thick data generating nine themes, two of which are reported on in this article.

Trustworthiness was ensured by selecting key informants from various organisations and institutions intervening in food security in Voi Division, collecting thick data with appropriate data collection methods, using self-reflexivity on issues that could hinder objectivity in the interpretation, and member checking (Lietz \& Zayas, 2010; Schurink, Fouché \& De Vos, 2011; Anney, 2014).

\section{Ethical considerations}

Ethical considerations for the study included the signing of informed consent forms, indicating voluntary participation, and assuring the participants of confidentiality, protection of their anonymity and debriefing, as suggested by Strydom (2011). In this regard, Beins and McCarthy (2018:35) point out that one way of recording the fact that a researcher has informed the participants fully and that they voluntarily agree to take part in the study is through the informed consent form. Ethical approval was granted by the Research Ethics Committee of the Faculty of Humanities, University of Pretoria (Reference No. 13356829/GW 20160525HS) and permission to conduct the research in Taita-Taveta County, Kenya, was granted by the Kenya National Commission for Science, Technology and Innovation (Ref No. NACOSTI/P/16/10047/9304). The authors declare that they have no conflict of interest.

\section{RESULTS AND DISCUSSION}

The thematic analysis of two themes selected from the qualitative data, namely (i) Dietary diversity among FHHs, and (ii) the status of food security among FHHs, is presented below, commencing with a broad biographical profile of the key informants.

\section{Biographical profiles of key informants}

The age group of the participants (key informants) ranged from 26 to 50 years, with the majority (13), aged 30 to 50 years. One was 26 years old. The age range in the inclusion criteria coincides with the recommended age for employees in the public service in Kenya (Republic of Kenya, 2016:64).

Both genders were represented, but 11 of the 14 participants were male, and only 3 were female. The male to female gender ratio of 11 to 3 is not quite commensurate with the $1 / 3$ Gender Rule stated in the Constitution of Kenya, 2010 (National Council for Law Reporting, 2013), which indicates that in every sector of human resource production, the government endeavours to have a gender-balanced civil service (Republic of Kenya, 2016:32), with not more than 2/3 of jobs filled by either gender. Hence, the result may not conclusively represent the actual situation in Voi Division. Participants held the positions of food security field monitors, food disaster response officers and crop development officers. McKenna and Main (2013:4) regard key informants as essential in community-based research, because such individuals can provide credible information about the community.

The highest level of education of half (7) of the key informants was a Bachelor's degree from a university, four had a tertiary diploma, one a Master's degree, one an advanced certificate, and one a certificate. Levels of education were associated with levels of expertise among key informant participants, who were deemed to be well educated, providing credible information on food security.

The thematic analysis of the two themes with their sub-themes is presented below. Participants (P) are numbered for the sake of anonymity, and they are quoted verbatim in italics.

\section{Theme 1: Dietary diversity among FHHs}

Dietary diversity is a central theme in food security, but specifically encompassed in the third dimension - food utilisation, which FAO (2008:1) describes as "Sufficient energy and nutrient intake by individuals is the result of good care and feeding practices, food preparation, diversity of the diet and intra-household distribution of food". 
Emergent sub-themes of the theme include food items, acceptable dietary diversity, poor dietary diversity, the dietary diversity among rural FHHs versus that among urban FHHs, and coping strategies.

\section{Food items}

This sub-theme explored the food items consumed in FHHs from different food groups to be as follows:

Maize (ugali) takes the lead. (P1)

They mostly eat maize meal. (P5, P11)

Maize is the major.(P9)

Several participants found the most common food items consumed in the diets of FHHs to be maize, which is part of the cereal food group. Maize was consumed either as whole maize, or pounded, or as flour (which makes ugali and "white porridge").

Other food items consumed in the FHHs included:

Maize, beans, green grams and pigeon peas and cow peas. To some extent they grow a lot of green grams. Maize takes the lead. (P1)

Ugali and greens, and porridge for the under-fives. Just white flour for under-fives, but a few of them use the one from millet or sorghum. (P3)

The universal ugali, rice, sweet potatoes, Irish potatoes, cabbage.(P4)

Maize meal (ugali) - supper: previous night's ugali (kiporo): morning and taken with tea as breakfast, lunch: a mixture of whole maize and pulse (ugali, githeri), a mixture of pounded maize and pulse (pure/muthokoi). (P10)

The food items mentioned above (together with their food group) included maize, wheat, rice and millet (cereals); sweet potatoes, Irish potatoes and green bananas (roots and tubers); beans, green grams, pigeon peas and cow peas (pulses); kale, cabbage, tomatoes and indigenous vegetables such as dandelion (mchunga) (vegetables). Maize was the most common food item consumed.

\section{Acceptable dietary diversity}

A few participants indicated rare cases of acceptable dietary diversity:

The diet is balanced, awareness was created, so everybody knows about nutrition, there are no cases of malnutrition. (P10)

We are dealing with different people and different classes at the same time. Some are able and others not able - they are average. (P9)

Besides limited acceptable dietary diversity, as reported by P10, a case of borderline dietary diversity was observed by P9, determined by the socio-economic circumstances of the FHH.

\section{Poor dietary diversity}

The majority of participants indicated poor dietary diversity in the FHHs as follows:

Diet is compromised completely. Because a time like this, you know people take what they find on the table. They don't have that liberty to choose. So diet is an issue. For example if maize is the only food available, you won't hear somebody talking about fruit and every other thing. They just eat what is there! (P1)

Actually people here don't eat to get nutritious food but eat to fill their stomach ... because they don't eat fruits - they eat fruits when they are sick ... even if they have local poultry, they don't eat eggs, they keep them to sell. (P5)

In Voi, one, is a dry area so in terms of food there are challenges (chakula, kidogo kuna matatizo). (P6) 
The participants noted that some FHHs had poor dietary diversity and only eat what is convenient and available. Drought was also linked to the poor dietary diversity in the study area. FHHs rely mainly on maize, and the participants mentioned some of the difficulties that FHHs experience in obtaining foods which could provide a varied diet.

\section{Dietary diversity among rural FHHs versus urban FHHs}

The dietary diversity in FHHs in rural areas versus urban areas was explored. Participants responded as follows:

Voi is a town, but in the interior villages ..., especially in Maungu, vulnerability is very high. Because in Maungu, they depend on farming and currently the rain is not reliable. So the food is not there for the children. They are not getting [a] balanced diet. (P2)

Those who purchase are the people around the town, but the village level, they don't have that capacity ... the purchasing power. (P4)

Rural is a bit challenging .... I have been to places where people really don't know what is lunch, and in most cases not that they don't want, but because they can't afford. Either because there is no water ....water forms part of food. (P13)

The participants' responses made it clear that rural FHHs were more impoverished than urban FHHs, which resulted in differences in their dietary diversity status.

\section{Coping strategies}

The participants mentioned the following coping strategies that were used by FHHs in the study area to survive on their food: ... they are trying to survive in one way or the other, using the given resources that they have. (P9)

... in the morning they take what they had for supper and reserved it a little for the morning. (P1)

They normally reduce the size of the food. Because they want to eat more days, than to eat enough and then miss (food) the following day. (P2)

The community eat in the morning and in the evening. ( $\mathrm{P} 4)$

The coping strategies included eating left-overs, reducing the size of meals to spread the available food over more than one meal, and skipping some meals in a day (only eating one or two meals a day).

\section{Discussion of Theme 1: Dietary diversity among FHHs}

Household dietary diversity depends on food availability, access and stability, and is specifically related to actual food utilisation. This is because there could be food stability in terms of availability and accessibility, but if the food is not ingested, then it is of no use to the body.

The food items consumed by the FHHs were predominantly maize (a cereal) as the main food item, and in a few instances roots and tubers. Other foods consumed were pulses and vegetables as sources of protein and vitamins respectively. However, the participants were of the opinion that maize was the most convenient food and formed a major part of the FHHs' diets. This shows that dietary diversity was restricted and insufficient for adequate nourishment. Good food utilisation requires sufficient energy and nutrient intake by individuals, resulting from good care and feeding practices, food preparation, diversity in the diet and intra household distribution of food (FAO, 2008:1)

The dietary diversity among the FHHs was largely found to be poor. Few participants thought that dietary diversity was acceptable among the FHHs. They mentioned that such diversity depended on the socio-economic circumstances of the FHHs and where they resided, whether in a rural or urban area. Qureshi et al. (2015:395) warn that undernutrition plays a role in creating and maintaining poverty traps, identifying maternal and child undernutrition as the primary pathway by which poverty is transmitted from one generation to the next. Poor food access also increases the risk of low birth weight and stunting 
in children, associated with a higher risk of becoming overweight or obese later in life (FAO et al., 2018:26).

Policies that promote nutrition-sensitive agriculture and food systems are therefore needed, paying special attention to the food security and nutrition of children under 5 years, school-age children, adolescent girls and women, in order to halt intergenerational cycles of malnutrition (FAO et al., 2018:26).

Climate change is strongly linked to dietary diversity outcomes related to the quantity and quality of the food available. Chauvin et al. (2012:19) report that drought conditions are the main cause of the poor performance of cereal and oil crop yields in Kenya, which experiences droughts every 5 to 7 years. The drought prevalence in Kenya as a factor of poor dietary diversity has also been described by the FAO (2016:51), because climate changes alter rainfall and water availability patterns, which in turn affect efforts to improve sustainable food productivity. In the context of the ecological systems perspective, climate change links the FHHs micro systems to the food security exo system.

The findings reported above indicate that, in order to ensure household dietary diversity, gender-based food policies and plans are urgently needed, especially in rural communities. Social workers need to understand the importance of food security in their developmental work (Ragan \& Dimitropoulus, 2017), as a potential benefit to both the profession and society. Informed social workers can help to provide or facilitate interventions on malnutrition, from whatever cause, whether preventive or through care after instances occur.

Dietary diversity among rural FHHs versus urban FHHs differed. FHHs in rural areas were deemed to have poorer dietary diversity, and to suffer more extreme poverty than those in urban areas. Chauvin et al. (2012:1) emphasise that in Africa, rural populations have not been able to move out of poverty principally because they have not transformed their basic economic activity, which is agriculture. It is therefore not surprising that Njeru (2020) points out that two thirds of food-poor individuals in Kenya are found in rural areas. Similarly, Mutavi et al. (2013:209) state that $80 \%$ of poverty-stricken Kenyans live in the rural areas; they argue that the main contributing factors to poverty among women in Kenya are low literacy levels and the death of the bread-winner. As the FAO (2008:3) notes, poverty is a cause of hunger, but conversely, a lack of adequate or proper nutrition (or poor dietary diversity) is an underlying cause of poverty.

The finding that the dietary diversity of FHHs in the study area was compromised is consistent with the findings of Ntwenya, Kinabo, Msuya, Mamiro and Majili (2015:9), who reported a higher factor loading on cereal grain consumption than on other food groups, irrespective of season, in their study in Tanzania. The predominance of cereals in the diet in the current Kenyan study and Ntwenya et al.'s (2015) Tanzanian study corroborate Chauvin et al.'s (2012:35) contention that vegetables are not widely consumed in sub-Saharan Africa, accounting for only $1.18 \%$ of people's total caloric supply. Vegetable consumption has been decreasing in the last 40 years, mostly associated with a preference for heavy starches such as maize, cassava, and yam, which quickly satisfy hunger and supply the necessary energy (Chauvin et al., 2012:35).

Maize makes up 65\% of the total food calories consumed by households in Kenya (Njeru, 2019), as it is the cheapest source of calories among cereal grains. However, the demand for this grain cannot be met fully, as maize is only produced on $40 \%$ of the total crop area by smallholders (Njeru, 2019). Kenya imports about $90 \%$ of its total rice supply, and $75 \%$ of its total wheat supply, but produces most of the total maize supply itself, importing only $10 \%$ (Njeru, 2020). This means that rice and wheat, as a complement to the maize, are less affordable.

Kenya has a comparative advantage in the global market, in that it manufactures processed agricultural products (Chauvin et al., 2012:19), including coffee, tea, sugar and dairy products (World Bank, 2015). For that reason, it has directed most of its resources towards those sectors to the detriment of the local food production sector. The main foods produced in Kenya are beans and pineapples, which are mainly 
exported, while potatoes, tomatoes, mangoes and bananas are produced, but not exported on a large scale (World Bank, 2015). As long as food production for export and the processing of agricultural products is a priority, there will continue to be limited dietary diversity in the local market. The lack of fruit availability among the Kenyan population is one probable reason why FHHs hardly consume fruit.

Coping strategies of the FHHs to survive despite the lack or insufficiency of food included reducing the size of meals, eating left-overs and skipping meals in a day. These coping strategies are evidence of poverty, hunger and food insecurity. People who are hungry are usually food deprived and food insecure, and this situation could lead to malnutrition.

Women play a central role in food security and are often the first to stop eating sufficiently in order for their children to get priority, but the women's wellbeing is affected. Furthermore, if food security is poor, women's health is significantly compromised, placing them at risk of maternal death or at great risk of obesity from poor nutrition in a poor environment (Aguirre, 2000).

The UN (2018:10) reports that globally hunger levels are rising again, following a prolonged period of decline, as more people suffer food insecurity, especially in sub-Saharan Africa. It is evident that food insecurity is on a downward spiral, as a consequence of widespread poverty and ecological factors, such as droughts, which diminish crop yields, as was rightly highlighted by the participants. This means that the need for the eradication of hunger and food insecurity through the SDGs is particularly urgent in Kenya.

The theme of dietary diversity among the FHHs illustrates a networked interrelation between the subthemes - food items consumed, dietary diversity, dietary diversity in rural versus urban FHHs, and coping strategies, to illustrate the roles they play in food security, especially among FHHs. The indicators of dietary diversity provide insight into the exo systems from an ecological systems perspective, as these indicators are influenced directly or indirectly by both human and physical ecological systems.

\section{Theme 2: Status of food security among FHHs}

The status of food security is an indicator used to monitor food security. Data yielded the following two food security sub-themes among the FHHs

- moderate food insecurity, is when people face uncertainties about their ability to obtain food, and have been forced to compromise on the quality and/or quantity of the food they consume (FAO et al., 2019:xiv); and

- $\quad$ severe food insecurity, is associated with the concept of hunger (FAO et al., 2019:xiv).

\section{Moderate food insecurity status}

Evidence for moderate food insecurity status among some Kenyan FHHs was found in the following comments by participants:

I can say 50:50, because there are areas they don't get food so they depend on relief food so I can't say .... I can say 50:50 ... but eh sometimes with the situation we are right now, sometimes droughts - lack of rains sometimes, it goes to 60 to 65. So far the WFP and the World Vision have reduced the tendency of giving the community food-that means the situation is not that bad. (P12)

Moderate because of those in towns and severe for those living in the rural; 50 percent is insecure. (P14)

\section{Severe food insecurity status}

A vast majority of the participants indicated that the food security status among the FHHs was in fact severe food insecurity:

Severe, bad! (P1, P5)

Voi Sub-county is food insecure. (P3) 
... for now food security is poor and this is because of drought. (P4)

Currently there is a problem, currently it is dry completely (kabisa)! There is nothing particularly in Voi there is nowhere people will get food apart from buying. (P6)

A number of the participants argued that the status of food security in the FHHs was moderate food insecurity. The reasons given were that some FHHs were receiving food relief from external agencies, or were self-reliant in some form or another. However, it was the opinion of most of the participants that food insecurity was not even moderate (it was worse), and that there was severe food insecurity in places. Drought was the reason most suggested as the root of this food insecurity.

\section{Discussion of Theme 2: Status of food security in FHHs}

The prevalence of only moderate food insecurity and severe food insecurity suggests poor food security among a vulnerable group, the FHHs. Njeru (2020) emphasises that people earning a low income are particularly vulnerable and are often unable to consume enough calories for a healthy lifestyle, which affects many Kenyans, as the KNBS estimates about 12 million people in Kenya are food poor.

Agricultural seasons influence food (in)security (Ntwenya et al., 2015:9), and persistent droughts in Kenya were a factor mentioned by the participants. It is therefore worth noting that the KNBS (2014:89) reports that the national maize output was $16 \%$ below the five-year average in 2014 because of poor rainfall. Droughts are extreme climate events characterised by prolonged periods of rainfall deficits that result in food insecurity and malnutrition, largely through cascading negative effects on agricultural production, food prices, value chains, water supplies and livelihoods, affecting access to income and food (FAO et al., 2018:47).

Climate variability and extremes are thus a key driver behind the rise in global hunger and one of the leading causes of severe food crises, which negatively affect all dimensions of food security, as well as reinforcing other underlying causes of malnutrition related to child care and feeding, health services and environmental health (FAO et al., 2018:xvi). This illustrates a complex network of ecological challenges relevant to household food security, especially among FHHs.

Addressing food insecurity is challenging because of all the disciplines involved (Kaiser, 2011), sometimes with competing interests within complex global food systems. Enhancing community food security is recommended as a framework and intervention strategy to address interrelated social, economic and environmental issues. Equitable access to healthy foods grown in a sustainable, environmentally friendly way is key (Kaiser, 2011) and can be a solution to economic development and equitable resource distribution.

\section{CONCLUSIONS AND RECOMMENDATIONS}

The main food item forming the diets of the FHHs was mainly maize with limited inclusion of other items for diversity. Pulses and vegetables were also available, but in lower quantities. Dietary diversity among the FHHs was rare and was mostly poor; FHHs in rural areas were more impoverished and their dietary diversity was even poorer than that of FHHs in urban areas. The coping strategies employed by these FHHs were intended to increase their resilience in times of food shortages.

The poor dietary diversity, particularly among the rural FHHs was strongly associated with recurrent droughts. These droughts jeopardise the four dimensions of food security (food availability, access, utilisation and stability) from working synergistically to form a conducive exo system of food security among the FHHs. Food utilisation was affected by the fact that maize was the staple food, with little food variation. Due to this underutilisation of diverse food items in the different food groups, insufficient nutrition was prevalent, which could lead to possible undernourishment.

The status of food security was found to be poor among the majority of the FHHs, which could have an impact on the nutritional status of household members, including children, leading to possible malnutrition. The FHHs were likely to be caught up in poverty traps, which emphasises how poverty, 
hunger and malnutrition as ecological sub-systems, acting as both causes and effects, are related to food insecurity as the FAO (2008:3) warns. The existence of food assistance to the FHHs indicates food insecurity vulnerabilities, which are factors that impede socio-ecological development among the FHHs and that require urgent intervention.

Access to safe, nutritious food is therefore emphasised as a human right, and priority should be given to FHHs as one of the most vulnerable groups, especially those residing in rural areas. Women play a central role in maintaining food security and, as the findings of this study indicate, the women in the FHHs in the study area used some detrimental coping strategies, such as skipping meals in a day to stretch out their meagre food resources and create familial resilience to food shortages. Under such circumstances, food insecurity is a social justice issue that social workers have an ethical obligation to address.

Policies that promote nutrition-sensitive agriculture and food systems are needed, paying special attention to the food security and nutrition of children under five years, school-age children, adolescent girls and women in order to halt the intergenerational cycle of malnutrition and poverty (FAO et al., 2018:26). The FAO (2008:3) argues that a strategy for attacking poverty in conjunction with policies to ensure food security offers the best hope of swiftly reducing mass poverty and hunger. Recent studies show that economic growth alone will not take care of the problem of food security. What is needed is a combination of income growth, supported by direct nutrition interventions and investment in health, water and education (FAO, 2008:3). Similarly, a network of intervention strategies are needed to ensure food security among the FHHs.

The aim of the study - to investigate and describe food security among FHHs in Voi Division, TaitaTaveta County, Kenya, from an ecological systems perspective - was achieved in the larger doctoral study (Icheria, 2019), where practice guidelines were provided to address the research gap for practitioners from various fields, to understand and adapt services to contribute towards improving food security among FHHs as a vulnerable group. The research question - what is the status of food security among female-headed households in Voi Division in Taita-Taveta County, Kenya? - was answered here in discussing two themes.

Thus the environmental and human systems, as proposed from an ecological systems perspective, should form linkages in practice, for the planning and implementation of initiatives to address SDG1 and SDG2. Food security is central to the 2030 Agenda and can be linked to all the SDGs (FAO et al., 2018:13), because proper food security lays the foundation for achieving a number of outcomes:

Improvements in food security among the FHHs directly support

- playing a role in ending poverty (SDG1), because good food security results in higher labour productivity, greater mental capacity and longer, healthier lives;

- $\quad$ ensuring healthy lives (SDG3);

- ensuring quality education (SDG4) through child school retention;

- achieving gender equality (SDG5) and reducing inequalities (SDG10) of all genders and addressing sectoral inequalities in food security; and

- promoting economic growth (SDG8).

Food security among FHHs is thus the lifeblood of sustainable development and drives the changes needed for a more sustainable and prosperous future (FAO et al., 2018:13).

Practice and policy recommendations include

- enhancing understanding of how poverty, hunger and malnutrition relate to food insecurity among FHHs and fits within the developmental trajectory;

- combining community organisation, coalition-building, advocacy, community development, research and policymaking to identify challenges of food accessibility and mobilise resources within social networks; 
82

- being aware of the structural barriers that continually challenge self-reliance and strengthen FHHs by advocating for government resources to enhance the micro and meso systems;

- using community work knowledge and skills to help communities, especially FHHs, achieve greater access to affordable, healthy food, for example, through teaching them how to grow and maintain vegetable gardens;

- addressing food insecurity as an issue of social justice and responding to the needs of those within communities, especially the FHHs, not just to have food, but to grow fulfilling, nutritious, culturally appropriate food; and

- including food diversity in assessments using measurement scales, for example, the Socio-Economic Empowerment Assessment (SEEA) and the Household Food Security Survey Model (HFSSM) to determine the level of Household Food Insecurity (HFI).

Recommendations for future research include

- conducting larger comparative studies of food security in FHHs between rural and urban settings nationally in Kenya or elsewhere in Africa; and

- determining the role social workers do or can play in the multi-disciplinary field of food security and developing guidelines for social work in this field.

\section{REFERENCES}

ADGER, W. 2003. Social capital, collective action and adaptation to climate change. Economic Geography, 79:387-404.

AGUIRRE, P. 2000. Socioanthropological aspects of obesity in poverty. In: PEÑA, M. \& BACALLAO, J. (eds). Obesity and poverty: A new public health challenge. Sci. Pub. 576. Washington, DC: Pan American Health Organization.

ANNEY, V.N. 2014. Ensuring the quality of the findings of qualitative research: Looking at trustworthiness criteria. Journal of Emerging Trends in Educational Research and Policy Studies, 5(2):272-281.

APAITIA-VAGUE, T. 2011. Social work and food: A discussion. Aotearoa New Zealand Social Work, 23(3):63-70.

BEINS, B. \& McCARTHY, M. 2018. Research methods and statistics. Cambridge: Cambridge University Press.

BESTHORN, F. 2013. Deep ecology's contribution to social work: A ten-year retrospective. International Social Welfare, 21(3):248-259.

BOOI, T.P. 2001. Kwashiorkor in children of single mothers: A medical social work study. Pretoria: University of Pretoria. (M mini-dissertation)

BRAUN, V. \& CLARKE, V. 2013. Successful qualitative research: A practical guide for beginners. London: Sage.

BRODY, A., HOSSAIN, N., OSWALD, K. \& SMITH, S. 2015. Innovations from the field: Gender mainstreaming from the ground up for the World Food Programme, Phase One: June 2013 -

September 2014: Synthesis Report. World Food Program, Institute of Development Studies \& Bridge Development $\quad$-Gender. [Online] Available: https://opendocs.ids.ac.uk/opendocs/bitstream/handle/20.500.12413/7089/wfp273602.pdf?sequence=29 4\&isAllowed=y [Accessed: 15/01/2019].

CHAUVIN, N.D., MULANGU, F. \& PORTO, G. 2012. Food production and consumption trends in sub-Saharan Africa: Prospects for the transformation of the agricultural sector. Working Paper 2012-011: February. United Nations Development Program: Regional Bureau of Africa. [Online] Available: 
https://www.undp.org/content/dam/rba/docs/Working\%20Papers/Food\%20Production\%20and\%20Con sumption.pdf [Accessed: 19/04/2020].

CHILTON, M., KNOWLES, M. \& RABINOWICH, J. 2015. The relationship between childhood adversity and food security: It's like a bird nesting in your head. Public Health Nutrition, 1(14):1-11. COUNIHAN, C. \& VAN ESTERIK, P. 2008. Food and culture: A reader. New York, NY: Taylor \& Francis.

DE CLERCK, H.M, WILLEMS, R., TIMMERMAN, C. \& CARLING, J. 2011. Instruments and guidelines for qualitative fieldwork: Project Paper 6b. University of Antwerp - Peace Research Institute Oslo: European Union Imagining Europe from the outside. [Online] Available: http://www.eumagine.org/outputs/PP6B\%20Instruments\%20and\%20guidelines\%20for\%20qualitative \%20fieldwork.pdf [Accessed: 06/12/2018].

DITEBO, G.P. 2010. Malnutrition in children: the perception of mothers in Botswana. Pretoria: University of Pretoria. (M mini-dissertation).

ELLIOTT, S. \& DAVIS, J. 2018. Challenging taken-for-granted ideas in early childhood education: A critique of Bronfenbrenner's Ecological Systems Theory in the age of post-humanism. In: MALONE, K. BARRATT HACKING, E. \& CUTTER-MACKENZIE, A. (eds). Research handbook on childhood nature: Assemblages of childhood and nature research. Cham: Springer:1-36. doi:10.1007/978-331951949-4_60-1

ETTEKAL, A. \& MAHONEY, J. 2017. The Sage Encyclopaedia of out of school learning: Ecological Systems Theory. Thousand Oaks, CA: Sage.

FAO (FOOD AND AGRICULTURE ORGANIZATION OF THE UNITED NATIONS). 2008. An introduction to the basic concepts of food security: Food security information for action: Practical guidelines. EC-FAO Food Security Programme. Rome: FAO. [Online] Available: http://www.fao.org/3/a-al936e.pdf [Accessed: 04/05/2020].

FAO (FOOD AND AGRICULTURE ORGANIZATION OF THE UNITED NATIONS). 2016. The state of food and agriculture: Climate change, agriculture and food security. Rome: FAO. [Online] Available: http://www.fao.org/3/a-i6030e.pdf [Accessed: 11/08/2018].

FAO (FOOD AND AGRICULTURE ORGANIZATION OF THE UNITED NATIONS), IFAD (INTERNATIONAL FUND FOR AGRICULTURAL DEVELOPMENT), UNICEF (UNITED

NATIONS CHILDREN'S FUND WORLD FOOD PROGRAMME, \& WHO (WORLD HEALTH ORGANIZATION). 2018. The state of food security and nutrition in the world 2018: Building climate resilience for food security and nutrition. Rome: FAO. [Online] Available: https://www.who.int/nutrition/publications/foodsecurity/state-food-security-nutrition-2018en.pdf?ua=1

[Accessed: 11/05/2020].

FAO (FOOD AND AGRICULTURE ORGANIZATION OF THE UNITED NATIONS), IFAD (INTERNATIONAL FUND FOR AGRICULTURAL DEVELOPMENT), UNICEF (UNITED

NATIONS CHILDREN'S FUND WORLD FOOD PROGRAMME, \& WHO (WORLD HEALTH ORGANIZATION). 2019. The state of food security and nutrition in the world 2019: Safeguarding against economic slowdowns and downturns. Rome: FAO. [Online] Available: http://www.fao.org/3/ca5162en/ca5162en.pdf [Accessed: 01/07/2020].

HADLEY, C., MULDER, M.B. \& FITZHERBERT, E. 2007. Seasonal food insecurity and perceived social support in rural Tanzania. Public Health Nutrition, 10:544-551.

HADLEY, C., STEVENSON, E.G.J. \& TADESSE, Y. \& BELACHEW, T. 2012. Rapidly rising food prices and the experience of food insecurity in urban Ethiopia: Impacts on health and wellbeing. Social Science and Medicine, 75(12):2412-2419. doi: 10.1016/j.socscimed.2012.09.018 
HAWKINS, R.L. \& KIM, E.J. 2012. The socio-economic empowerment assessment: Addressing poverty and economic distress. Clinical Social Work Journal, 40:194-202.

HIMMELHEBER, S. 2014. Examining the underlying values of food security programming: Implications for social work profession. Journal of Progressive Human Services, 25:116-132.

ICHERIA, B.K. 2019. An investigation into food security among female-headed households in Kenya: A case of VOI division in Taita-Taveta County. Pretoria: University of Pretoria. (PhD thesis).

JACOBSON, M. 2007. Food matters. Journal of Community Practice, 15(3):37-55.

KAISER, M. 2011. Food security: An ecological-social analysis to promote social development. Journal of Community Practice, 19(1):62-79. doi:10.1080/10705422.2011.550261

KNBS (KENYA NATIONAL BUREAU OF STATISTICS). 2014. Status report on the Kenya national food security: Zero tolerance to hunger. Kenya Constitution Article $43(1)(C)$. Nairobi: Africa Women's Studies Centre, University of Nairobi.

KNBS (KENYA NATIONAL BUREAU OF STATISTICS). 2019. Kenya Population and Housing Census Vol. 1: Population by county and sub-county. Nairobi: KNBS. [Online] Available: http://www.knbs.or.ke [Accessed: 12/05/2020].

KOSTER, J.M. \& LECKIE, G. 2014. Food sharing networks in lowland Nicaragua: An application of the social relations to count data. Social Networks, 38:100.

LESSA, F. \& ROCHA, C. 2012. Food security and gender mainstreaming: Possibilities for social transformation in Brazil. International Social Work, 55(3):337-352.

LIETZ, C. \& ZAYAS, E. 2010. Evaluating qualitative research for social work practitioners. Advances in Social Work, 11(2):188-202.

MCKENNA, S. \& MAIN, D. 2013. The role and influence of key informants in communityengaged research: A critical perspective. London: Sage.

MIDGLEY, J. 1995. Social development: The developmental perspective in social welfare. London: Sage.

MIKKONEN, J. \& RAPHAEL, D. 2010. Social determinants of health: The Canadian facts. Toronto: School of Health Policies and Management, York University. [Online] Available: http://thecanadianfacts.org/The_Canadian_Facts.pdf [Accessed: 23/11/2018].

MUTAVI, T., KOKONYA, D., OBONDO, A., WARIUA, P. \& OCHARO, R. 2013. The magnitude of poverty among female headed households in Yathui and Central Division, Machakos District, Kenya. International Journal of Business and Social Science, 4(6):208-211.

MWANIKI, A. 2015. Achieving food security in Africa: Challenges and issues. [Online] Available: http://www.wageningenportals.nl/sites/default/files/resource/achieving_food_security_in_africa.pdf [Accessed: 07/03/2017].

NASW (NATIONAL ASSOCIATION OF SOCIAL WORKERS). 2017. Code of Ethics of the National Association of Social Workers (Rev. Ed.). [Online] Available: www.socialworkers.org/pubs/code [Accessed: 30/04/2020].

NATIONAL COUNCIL FOR LAW REPORTING. 2013. Constitution of Kenya, 2010. Nairobi: National Council for Law Reporting (Kenya Law). [Online] Available: http://kenyalaw.org:8181/exist/kenyalex/actview.xql?actid=Const2010 [Accessed: 17/06/2017].

NEAL, J. \& NEAL, Z. 2013. Nested or networked? Future directions for ecological systems theory. Social Development, 22(4):722-737. doi:10.1111/sode.12018 
NIEUWENHUIS, J. 2020. Qualitative research designs and data gathering techniques. In: MAREE, K. (ed.). First steps in research. $3^{\text {rd }}$ ed. Pretoria: Van Schaik.

NJERU, T.N. 2019. Understanding the political economy of maize in Kenya. The Conversation, July. Johannesburg. [Online] Available: https://theconversation.com/understanding-the-political-economyofmaize-in-kenya-120336 [Accessed: 30/04/2020].

NJERU, T.N. 2020. Why Covid-19 is another blow for Kenya's food security. The Conversation, April. Johannesburg. [Online] Available: https://theconversation.com/why-covid-19-is-another-blowforkenyas-food-security-135567 [Accessed: 15/05/2020].

NOLIN, D.A. 2010. Food sharing networks in Lomaleraa, Indonesia: Reciprocity, kinship and distance. Human Nature, 21:243-268.

NTWENYA, J.E., KINABO, J., MSUYA, J., MAMIRO, P.\& MAJILI, Z.S. 2015. Dietary and household food insecurity in rural populations of Kilosa District, Tanzania. Plos One, 10(5). DOI:10.1371/journal.pone.0126038.

PAUL, K.M. 2011. Food insecurity and clinical social work. Northampton: Smith College. (M thesis). [Online] Available: https://scholarsworks.smith.edu/theses/1008 [Accessed: 25/03/2020].

PHILLIPS, R. 2009. Food security and women's health: A feminist social work. International Social Work, 52(4):485-498.

QURESHI, E., DIXON, J. \& WOOD, M. 2015. Public policies for improving food and nutrition security at different scales. Food Security, 7(2):393-403.

RAGAN, E. \& DIMITROPOULOS, G. 2017. A critical look at food security in social work: Applying the socio-ecological lens. Journal of Undergraduate Research in Alberta, 6:1-12.

REPUBLIC OF KENYA. 2011. National food and nutrition security policy. Nairobi: Government Printer.

REPUBLIC OF KENYA. 2016. Public Service Commission: Human Resource Policies and Procedures Manual for the Public Service. Nairobi: Government Printer.

RICHES, G. 2001. Food banks and food security: Welfare reform, human rights and social policy lesson from Canada. Social Policy and Administration, 36(6):648-663.

RIDEOUT, K., RICHES, G., OSTRY, A., BUCKINGHAM, D. \& MACRAE, R. 2007. Bring home the right food in Canada: Challenges and possibilities for achieving food security. Public Health Nutrition, 10(6):566-573.

ROSEGRANT, M. \& CLINE, S. 2003. Global food security: Challenges and polices. Science, 302:19171919.

SCHURINK, W., FOUCHÉ, C.B. \& DE VOS, A.S. 2011. Qualitative data analysis and interpretation. In: DE VOS. A.S., STRYDOM, H., FOUCHÉ, C.B. \& DELPORT, C.S.L. (eds) 2011. Research at grass roots for the social sciences and human service professions. $\left(4^{\text {th }} \mathrm{ed}\right)$. Pretoria: Van Schaik.

SHERMAN, M., FORD, J., LLANOS-CUENTAS, A. \& VALDIVIA, M.J. 2016. Food system vulnerability amidst the extreme 2010-2011 flooding in the Peruvian Amazon: A case study from the Ucayali Region. Food Security, 8:551-570.

STRYDOM, H. 2011. Ethical aspects of research in the social sciences and human service professions. In: DE VOS. A.S., STRYDOM, H., FOUCHÉ, C.B. \& DELPORT, C.S.L. (eds) 2011. Research at grass roots for the social sciences and human service professions. $\left(4^{\text {th }} \mathrm{ed}\right)$. Pretoria: Van Schaik.

STRYDOM, H. \& DELPORT, C.S.L. 2011. Sampling and pilot study in qualitative research. In: DE VOS. A.S., STRYDOM, H., FOUCHÉ, C.B. \& DELPORT, C.S.L. (eds). 2011. Research at grass roots for the social sciences and human service professions. $\left(4^{\text {th }}\right.$ ed $)$. Pretoria: Van Schaik. 
TROSTLE, J.A., HUBBARD, A., SCOTT, J., CEVALlOS, W., BATES, S. \& EISENBERG, J.N. 2007. Raising the level of analysis of food borne outbreaks: Food sharing networks in rural coastal Ecuador. Epidemiology, 454:42-54.

UN (UNITED NATIONS). 2015. Transforming our world: The 2030 Agenda for Sustainable Development. New York, NY: UN. [Online] Available: ustainabledevelopment.un.org/post2015/transformingourworld/publication [Accessed: 07/06/2019].

UN (UNITED NATIONS). 2018. Sustainable development goal 6: Synthesis report 2018 on water and sanitation. New York, NY: UN.

WORLD BANK. 2015. Agriculture and food processing in Kenya. World Bank launch event. October. [Online] Available: https://issuu.com/kamkenya/docs/2015_10_23_agroprocessing_presenta [Accessed: 02/05/2020]

WORLD BANK. 2016. Taking on inequality: Poverty and shared prosperity 2016. [Online] Available:https://openknowledge.worldbank.org/bitstream/handle/10986/25078/9781464809583.pdf [Accessed: 11/05/2018]. 